Article

\title{
Optimal Multiple Attribute Decision Model for Key Parameters of Online Group Buying Product
}

\author{
Shen-Tsu Wang ${ }^{1, *}$, Meng-Hua $\mathrm{Li}^{2,3}$ and Chun-Chi Lien ${ }^{4}$ \\ 1 Department of Commerce Automation and Management, National Pingtung University, No.51, Minsheng E. \\ Rd., Pingtung City, Pingtung County 90004, Taiwan \\ 2 Department of Industrial Management \& Institute of Industrial Engineering and Management, National \\ Formosa University, Huwei, Yunlin 63201, Taiwan; mhli@nfu.edu.tw \\ 3 Smart Machine and Intelligent Manufacturing Research Center, National Formosa University, Huwei, Yunlin \\ 63201, Taiwan \\ 4 Department of Business Administrator, National Chung Hsing University, Taichung City 402, Taiwan; \\ d107023007@mail.nchu.edu.tw \\ * Correspondence: d917812@oz.nthu.edu.tw; Tel.: +886-8-7663800
}

Received: 26 August 2019; Accepted: 23 September 2019; Published: 27 September 2019

check for updates

\begin{abstract}
The rise of the internet has led to rapid development of online group buying, and with the various functions and analysis tools provided on the internet, consumers are making more purchases than ever before. In addition to attracting consumers to buy products or services via online shopping platforms, the industry's online group buying market allows customers to enjoy preferential prices together. Consumers can bargain through large-scale purchases. Through quantity-based pricing, the effect of the decline on consumers' expected price will be enhanced, and consumers will be able to purchase products at lower prices, which encourages more consumers to join group buying schemes. In terms of product cost, online shopping operations enable manufacturers to save shop setup and inventory costs, and some of these cost savings may be reflected in the selling price, which can enable customers to obtain products at lower prices. The grey decision model is used for further in-depth exploration. The purpose of this study is to use the grey correlation ranking and grey multi-attribute decision-making (TOPSIS) process to further determine the optimal shelf-time, inventory quantity, and selling price (key parameters) of commodities, in order to design a plan that makes maximum profit for the industry and provides the best service to customers.
\end{abstract}

Keywords: online group buying; grey correlation ranking; grey multi-attribute decision-making; key parameters

\section{Introduction}

According to the statistics of the industry, the output value of the Taiwanese group purchase market is more than NT $\$ 12$ billion if the group purchase website is conservatively estimated. No matter whether it is an offline or community platform, such as open group transactions that cannot be accurately calculated, it can be seen that the online group buying business opportunities are unlimited. For consumers, group buying activities can gather the power of the masses, order high-volume goods from sellers, lower the price of products, and obtain bargaining power to obtain the best buying conditions. For suppliers, consumers can spontaneously spread consumer information. While reducing the cost of enterprise marketing, this does not affect the number of orders. It is thus known that group purchases give both parties a win-win situation, and therefore, group buying has become a popular consumption pattern [1-3].

Online group buying is a very popular consumption method today. This is mainly due to the maturity of network technology and the objective analysis provided by the industry. Therefore, it 
attracts many people to participate in online group buying. Due to the large number of participating customers, the customers are unknown to each other. Therefore, risk analysis of the online group buying community is important [1]. As the number of users shopping with mobile devices has increased significantly, if customers feel that the inventories of group buying websites are decreasing, they will be more motivated to purchase a product. Therefore, this study explored the impacts of the different types of consumers engaging in group purchases on the internet as well as the inventory and prices of the purchase needs of consumers and applied the grey-based decision-making model for further in-depth exploration [4,5].

Sometimes stores deliberately introduce group buying with ultra-low prices, which seems unprofitable on the surface, but, in fact, these merchants can earn enough exposure and a high enough netizen reputation, which provides an alternative marketing method; however, as group buying orders are large, they test the stores' inventory capacity and the manufacturers' production capacity. Sacrificing product quality and after-sales service due to the requirement of fast delivery is more likely to result in negative comments from netizens. This study considers the marginal decline rate of the inventory-dependent demand $G_{0 i}$, the upper limit of demand $L$, and other parameters which affect the inventory quantity of group buying operators. Operators must also possess knowledge regarding the arrangement of shelf-time of many commodities, for example, in response to summer vacation, more amusement parks, water sports, and other tourism tickets will be introduced. In addition, the shelf-time of commodities with high similarity should be staggered; for example, you will not see two groups of spicy hot pot on the same day, which provides the best arrangement within a limited range. Therefore, this study considers the influence coefficients of different commodity prices on different demands $E$, different unit $\operatorname{costs} c$, and different commodity selling prices on the model. There are also many group buying websites in Taiwan (Gomaji, 17life, etc.) to help with marketing. "Group buying websites" will usually evaluate whether a providers' products have selling points before allowing them on the shelves for sale, and there will be a price checking process before product providers submit their products. The selling price given to group buying websites by product providers must be $20 \%$ off of the actual price after a market survey. Moreover, group buying websites require product providers to give prices for one piece and a combination of multiple pieces (for example, bracket combinations of 1 piece/4 pieces/6 pieces), which means that 1 piece must be $15-20 \%$ off the market price, four pieces must be $25-30 \%$ off of the market price, etc. In addition, depending on the product category, the commission will be about $15-20 \%$ (the logistics cost is borne by the product providers). Group buying websites have power, because they have loyal customers wanting bargains and their own marketing resources. A single product was once sold to nearly 2000 groups on Gomaji within a month. However, the disadvantage is that it is very difficult to sell a product at the original price after the group buying website breaks it down, as even if the cooperation ends, customers can still find the historical price recorded on the group buying website (consumers usually have an expectation psychology), which forms the consumer's mentality of waiting for anniversary discounts. Therefore, this study focuses on the selling price of online group buying products and considers various parameters, such as the upper limit of demand $L$, the unit $\operatorname{cost} c$, the influence coefficient of price on demand $E$, etc. This study uses the grey correlation ranking method and grey multi-attribute decision-making (plan selection) to further plan the optimal shelf-time, inventory quantity, and selling price (key parameters) of commodities in order to design a plan that makes maximum profit for the industry and provides the best service to customers [6-12].

\section{Literature Review}

Research has shown that, through the collective shopping mechanism of the internet, sellers can reduce the cost of recruiting customers and buyers can purchase products at lower prices [13]. Liaw et al. [14] found that, in the online shopping environment, perceived risk has a significant impact on consumers' willingness to purchase; if consumers have a lower perceived risk, they will be more willing to purchase items on the internet. Chen et al. [15] discussed the preconditions of online group 
buying willingness and found that the content of reviews on the website and the number of existing orders will influence the perceived risk and perceived trust, which will, in turn, affect the willingness to join group buying schemes. Group buying assembles groups of consumers who have similar goals or interests, and therefore, the purchasing power of the group is voluntarily assembled to negotiate with specific suppliers to obtain more favorable prices [5].

Kauffman and Wang [4] suggested that group buying attracts consumers in two ways: (1) the group purchase price is lower than the marked price of a retail store; and (2) engaging in group buying makes the customer feel that they have the ability to negotiate prices with suppliers. Suppliers can stimulate greater consumer demand and purchases under a pre-committed price-to-quantity mechanism that maximizes revenue; therefore, both consumers and suppliers can use the group purchase mechanism to make money [1]. One e-commerce model is the Customer + Customer to Business model (CC2B). The difference between the CC2B online buying platform and the B2CC online buying platform is that $\mathrm{CC} 2 \mathrm{~B}$ allows consumers to initiate group buying based on individual needs. Currently, there are two common types of group bidding for CC2B online group purchases. First, a group purchase is initiated by a certain main purchaser on a group buying platform, which initiates the purchase of a certain product. The main purchaser is responsible for calling users who are interested in purchasing the product, recording the number of purchases, and finally, placing the orders with the seller. The main purchaser must represent the users of the group and negotiate with the seller for price, product quality, ordering and delivery dates, and other matters as well as consolidating the group members' information, dealing with payment issues, and informing the group members of order deadlines and delivery locations. Under this group buying model, group members may not know each other, and the process may be complicated. Second, a group purchase is initiated by a main purchaser, which is then jointly purchased by friends, co-workers, classmates, or other people that the main purchaser knows, and then, group buying is opened on a group purchase platform. Although this group buying process also includes the above procedures and steps, it is easier to implement and is less complicated because the members are acquainted with each other.

In the past, most research on online group buying issues emphasized the characteristics of using the internet to increase the purchasing power of groups of strangers; therefore, the purchasing situations mostly belonged to the B2CC e-commerce model or the first group buying model of the above CC2B e-commerce models [4,5]. In reality, numerous cases of group buying occur in daily life, such as among office colleagues, friends, family, schoolmates, etc. Such cases belong to the second group purchase model of $\mathrm{CC} 2 \mathrm{~B}$, as mentioned above. In this type of group buying, it is usually one person (the main purchaser) who initiates the group purchase of a product and invites other people to join the group; therefore, the main purchaser and the group buyers are acquainted. Since less research has focused on the online group buying model initiated by acquaintances and friends, research from different perspectives and an appropriate theoretical basis could aid in the theoretical development and practical applications of this topic in the future. Since most previous studies of online group buying were based on groups of strangers (consumers), scholars have often discussed the opinions and interest exchanges of netizens, human interactions, and social relations from the perspective of virtual communities or online communities [16].

In this group buying model, the product to be purchased might not be the same each time, and the members of each group purchase team could be different. Therefore, each time individuals face a group purchase, they will form a purchasing decision based on the product characteristics of the group formed at that time. Under the theory of the reference group, the phenomenon of an individual being affiliated with several reference groups at the same time can be more accurately reflected in daily life. Therefore, after considering the relevant theories of social relations, this study proposes that the discussion of reference groups is more consistent with the influence of the group on individual purchase decisions within the group buying activities, as initiated by colleagues, friends, or family, because the socialization process is affected by reference groups, and the social context to which individuals belong will shape consumer behaviors and influence individual purchase decisions [17]. 
Group buying, which is a popular activity, means consumers unfamiliar with each other are willing to cooperate on the internet to obtain products/services with lower discounts on online shopping platforms, such as Groupon, which advertises at least one super discount per day for products and services. With the help of mobile communications and new forms of social media (such as Facebook and Plurk), it has aroused even more responses from online consumers. Online group buying is different from traditional B2C online shopping, as its trading behavior involves a three-party relationship among group purchase websites (group buying website), cooperating stores, and consumers. Therefore, when group buying networks bring large orders to the stores, some stores may fail to meet the needs of the consumers due to over ordering and a lack of production capacity [18]. Sahay [19] pointed out that online group buying breaks geographical limitations, makes the price of the agreement more flexible, and allows consumers to have better buying conditions. Past research has also pointed out that the price of a product will affect the consumer's perceived fairness, and thus, will influence their purchase willingness [20-22]. Traditional group buying is limited by territory; therefore, it is usually arranged with friends, family members, or colleagues who have the same needs in order to achieve the goal of reducing the purchase price $[4,23,24]$. For the product providers, time is the reason for the loss of consumers, as consumers have varying degrees of wait-acceptance when they have different waiting expectations [25].

The grey system theory focuses on the relational system model of ambiguity and the incomplete information system and conducts a relational analysis and model construction on the basis of prediction and decision-making. To understand the situation of the system so that the gray correlation analysis method can effectively deal with the uncertainty of things, multivariate input, discrete data, and data incompleteness are used. The grey theory research category is mainly divided into six parts: (1) grey generation; (2) grey relational analysis; (3) grey modeling; (4) grey prediction; (5) grey multi-attribute decision making; and (6) grey control [6,8,26-28]. The basic feature of gray theory is the ambiguity of the system's information. In the grey theory system, information consists of two structures: one is an incalculable part, that is, the image is expressed; the other is a measurable part, that is, the data part of the information is expressed. In terms of the imagery of information, the grey theory holds that the system lets us know that it is usually an insufficient or partial image component. As far as the scale of information is concerned, grey theory points out that in terms of the measurement scale of the system, usually only one interval can be taken, and there is no way to obtain the exact value. The central problems that must be dealt with by the gray theory include the rise and fall of the country, economic, social, educational, and political factors. There are many variables in each system. Humans have limited understanding and mastery of the system, which represents a small part of the system or incomplete information. They can be regarded as only receiving part of the signal of the system. Other parts are miscellaneous (noise). The general statistical method used is to treat the noise as a residual term in the pattern. Compared with statistical methods, grey theory is characterized by the fact that the researcher has not fully been informed about the facts. In the case that the system is not fully understood, the small sample abnormal state (small and non-specifically distributed data) can still be used for the grey system. For theoretical analysis, on the contrary, the statistical probability method must use a large amount of data to find the regularity, and usually, there is a hypothesis that the data is normally distributed or close to the normal distribution. When the amount of data is insufficient, the statistical method is regarded as including the error in the change that does not conform to the regularity of items (or residuals), but also there is too little information to determine whether it is representative $[6,8,26-28]$. Grey relational analysis (GRA) is a quantitative comparative analysis of the developmental dynamics between grey system factors. It is based on the similarity or relative degree among the factors and the method of measuring the degree of the relationship among factors. It presents the various relationships among the relevant factors of the system as system decisions and predictive control, thereby providing useful information and a more reliable basis. Because the grey correlation analysis is based on the trends of development of various factors, a large number of data samples is not required. A good distribution law for the samples obtained is also not required, so the 
amount of calculation required is small and does not occur. The results of the quantitative analysis of the grey scale and the results of the qualitative analysis do not occur. For the factors between the systems, the degree of change over time or with different objects is measured. In the process of system development, if the trend of change between factors is coherent, that is, the degree of synchronous change is higher, it can be said that the degree of the relationship between the two is higher; otherwise, it is lower. In grey multi-attribute decision-making, according to the characteristics of the factors, the choice of the upper limit effect measure, the lower limit effect measure, and the specific center effect measure can be considered, and most options can be chosen $[6,8,26-28]$.

\section{Research Method}

In the online group buying feature, the relationship between demand and inventory is very important, so $G_{0 i}$ is used as the marginal decline rate of demand due to inventory. $A_{j}$ is the demand for different stages, the upper limit effect measure, the lower limit effect measure, and the specific center effect measure, and TOPSIS $\left(T C_{j}^{*}\right.$ ) describes the way that professional managers subjectively give weights $[6,8]$.

\subsection{Grey Correlation Ranking}

The analysis of the factors of online group buying showed that the factors considered are likely to have the following characteristics. They are based on the similarity or relative degree among the factors and the method of measuring the degree of the relationship among factors. The various relationships are presented as a system of decision making and predictive control, thereby providing useful information and a more reliable basis. The obtained sample does not require a good distribution law, so the amount of calculation required is small, and it does not occur in cases where the results of quantitative and qualitative analyses do not require a measure of the magnitude of the change over time or from different subjects $[2,6,8]$.

The degree of relevance between factors was determined using the grey correlation ranking method to identify the key factors affecting the system's operation and to further analyze the key characteristics of the research variations. The research steps are described as follows [6,8]:

Step 1: Normalize the initial data, as shown in Equation (1):

$$
A_{i}(l)=\frac{y_{i}(l)}{\sum_{l=1}^{N} \frac{y_{i}(l)}{N}}, i=a, \ldots, d \quad l=1, \ldots, N
$$

Step 2: Calculate the difference sequence with the specified standard column as the base. Use the average of the 0th column as the standard column. The difference sequence $\Delta_{0 i}(l)$ is calculated, as shown in Equation (2):

$$
\Delta_{0 i}(l)=\left|A_{0}(l)-A_{i}(l)\right|, i=1,2,3, \ldots \quad l=1, \ldots, N .
$$

Step 3: Calculate the maximum difference $\Delta_{\max }$ and the minimum difference $\Delta_{\min }$, as shown in Equations (3) and (4):

$$
\begin{aligned}
& \Delta_{\max }=\operatorname{Max}_{i, l} \Delta_{0 i}(l) \\
& \Delta_{\min }=\operatorname{Min}_{i, l} \Delta_{0 i}(l) .
\end{aligned}
$$

Step 4: Calculate the grey correlation coefficient $C_{0 i}(l)$, as shown in Equation (5), where $z$ is the adjustment coefficient. In general, the coefficient value is taken as 0.5 ; however, in order to increase the difference of the results, the grey correlation coefficient can also be adjusted as needed. The grey correlation coefficient is the degree of correlation between the reference sequence and the comparison sequence; when the grey correlation coefficient is closer to 1 , it indicates that the correlation degree 
between the reference sequence and the comparison sequence is higher; when it approaches 0 , the correlation degree between the two becomes lower:

$$
C_{0 i}(l)=\frac{\Delta_{\min }+z \cdot \Delta_{\max }}{\Delta_{0 i}(l)+z \cdot \Delta_{\max }} .
$$

Step 5: Calculate the degree of correlation $G_{0 i}$ between each column and the standard column, as shown in Equation (6):

$$
G_{0 i}=\sum_{l=1}^{N} \frac{C_{0 i}(l)}{N} .
$$

Step 6: Sort the degree of each factor influencing the system according to the calculation results of grey correlation given in Step 5 .

\subsection{Grey Multi-Attribute Decision-Making: Plan Selection}

The plan selection method of grey multi-attribute decision-making refers to the combination of factors that make up all the possible decision-making factors in the process of multi-attribute decision-making when there are features with uncertain information in the scheme and then measures the effect of grey-based decision-making. After calculation and execution of the resulting combination of decisions, the decision-making matrix of the solution is used to determine the best solution. The calculation process first defines the decision-making factors of the plan. The grey multi-attribute decision-making scheme selection method defines the attributes as events, $\operatorname{defines}$ set $A$ as a set of events, and defines $d_{i}$ as one of multiple elements in a set of events, which is defined as one attribute $d_{i}, i=1,2, \ldots, n$. Multiple option plans are called countermeasures; set $B$ represents a set of multiple option plans, and $e_{j}$ is an element of a set of multiple option plans, which is represented by plan $e_{j}$, where $j=1,2, \ldots, m$. Each plan is displayed under the attribute as the influential content of the plan and is marked as $m_{i j}$ in the plan selection method of grey multi-attribute decision analysis, while the decision matrix $M=\left[m_{i j}\right]$ can be initially established according to the evaluation result of each plan under each attribute. This decision-making method must establish a preset standard column to calculate the grey correlation coefficient $C_{0 i}(l)$. The preset standard column is composed of $m_{i j}$, meaning the best estimation results according to the different properties under each attribute. Different calculation methods must be developed for the so-called definition of the best estimation results according to different properties by considering whether the objective of the attribute is large, small, or desirable. $A_{i j}$ represents the dependence calculation of each element in the series $\left\{m_{i 1}, m_{i 2}, \ldots, m_{i n}\right\}$ corresponding to each distinct attribute $d_{i}$ and the default standard column. The calculation of the effect measure, as based on the estimation of different properties, is divided into the upper limit effect measure, lower limit effect measure, or specific center effect measure. Equation (10) indicates the attribute factor ranking $\left(U_{i}\right)[6,8,26]$.

The upper limit effect measure is applicable when the requirement of the target effect is to be large (such as for quality, academic performance, etc.). Therefore, with the maximum result $u_{i}^{\max }$ of all plans using attribute $d_{i}$ as the corresponding key factor in the preset standard column, the definition of the upper limit effect measure is, as shown in Equation (7),

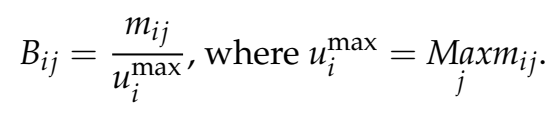

The lower limit effect measure is applicable when the requirement of the target effect is to be small (such as cost, noise, etc.). Therefore, with the minimum result $u_{i}^{\mathrm{min}}$ of all plans under attribute $d_{i}$ used 
as the corresponding key factor in the preset standard column, the definition of the lower limit effect measure is, as shown in Equation (8),

$$
B_{i j}=\frac{u_{i}^{\min }}{m_{i j}}, \text { where } u_{i}^{\min }=\operatorname{Minm}_{j} \text {. }
$$

The specific center effect measure is applicable when the requirement of the target effect is a specified target (such as humidity, body temperature, etc.). Therefore, with target $u_{i}^{\max }$ under attribute $d_{i}$ as the corresponding key factor in the preset standard column, the definition of the specific center effect measure is, as shown in Equation (9),

$$
B_{i j}=\frac{\operatorname{Min}\left\{m_{i j}, u_{i}^{*}\right\}}{\operatorname{Max}\left\{m_{i j}, u_{i}^{*}\right\}}
$$

From the above three different definitions, it can be seen that the value of the dissimilarity effect measure is between 0 and 1, and the larger the value is, the better the evaluation performance of decision-making plan $b_{j}$ under attribute $d_{i}$ is.

\subsubsection{Multi-Attribute Decision Matrix and Decision Criteria}

Decision matrix $F$ was built based on the effect measures of the estimation according to different properties $A_{i j}$; if there are $n$ key evaluation attributes, i.e., $d_{i}$, where $i=1,2, \ldots, n$ and $p$ are option plans, i.e., $e_{j}$, where $j=1,2, \ldots, p$, the decision matrix $F(n \times p)$ will be as shown in Equation (10)



After the formation of the decision matrix, as based on the estimation according to different properties, the best plan can be calculated and selected according to the decision criteria. In the grey multi-attribute decision-making analysis method, the decision criterion for selecting a plan is to choose the largest effect measure in attribute $d_{i}^{*}$ as the best solution, which means that, in the calculation of attribute $d_{i}^{*}, e_{j}$ is the best solution. As it considers the largest factor in each row, it is called the row decision, as shown in Equation (11):

$$
A_{j i^{*}}=\underset{j}{\operatorname{Max}} A_{i j}=\operatorname{Max}\left\{A_{i 1}, A_{i 2}, \ldots, A_{i p}\right\}
$$

In order to consider the integration results of all the properties of plan $e_{j}$ with the estimation according to different properties, consider the $T C_{j}^{*}$ weights of different properties, as shown in Equation (12). The calculation of $A_{j}$ is shown in Equation (13).

\subsubsection{Technique for Order Preference by Similarity to Ideal Solution (TOPSIS)}

Since the grey multi-attribute decision has not yet considered the opinions of professional managers, and TOPSIS includes the ways that professional managers subjectively give weights, the best solution is defined as all attributes having the best value. This study used TOPSIS and professional managers to identify possible factors that affect physical factors. The value measurement method of TOPSIS is based on the best ideal solution and the negative ideal solution. The ideal solution is to reach the maximum value of the large attribute and to reach the minimum value in the small attribute. For the convenience of calculation, after adjusting the small attribute to the desired value, the ideal 
solution $Q^{*}$ is the maximum value of all attributes, where the $h_{i j}$ standardized score after multiplying the weight is [8].

$$
Q^{*}=\left\{\max h_{i j} \mid i=1,2, \ldots, m\right\}=\left\{h_{i}^{*} \mid=1,2, \ldots, m\right\} .
$$

The distance from solution $j$ to the most ideal solution is the degree of separation $K_{j}^{*}$, and the distance to the negative ideal solution is the degree of separation, as defined.

$$
\begin{gathered}
K_{j}^{*}=\sqrt{\sum_{i=1}^{n}\left(h_{i j}-h_{i}^{*}\right)^{2}}, j=1,2, \ldots, o . \\
K_{j}^{-}=\sqrt{\sum_{i=1}^{n}\left(h_{i j}-h_{i}^{-}\right)^{2}}, j=1,2, \ldots, o .
\end{gathered}
$$

TOPSIS measures the distance between the best solution and the negative ideal solution by calculating the relative progress indicator and integrates the two degrees of separation in a proportional manner to measure the pros and cons of the solution. In other words, the closer a solution is to the most ideal solution and the farther away it is from the negative ideal solution, the better the solution is. This study defines $T C_{j}^{*}$ as shown in Equation (12)

$$
T C_{j}^{*}=\frac{K_{j}^{-}}{K_{j}^{*}+K_{j}^{-}}, j=1,2, \ldots, o
$$

where the measured $T C_{j}^{*}$ value is between 0 and 1 . The closer to 1 the value is, the further the solution is from the negative ideal solution. The closer to 0 the value is, the further the solution is from the ideal solution.

$$
A_{j}=\sum_{i=1}^{n} T C_{j}^{*} A_{i j}, \sum_{j} T C_{j}^{*} \%=100 \%
$$

The maximum solution $e_{j}$ under the combined results of $A_{j}$ in this method is the best choice, as shown in Equation (13). $A_{j}$ represents the demand of the solution, where $j=1,2, \ldots, p$.

\subsection{Model Derivation}

Symbol definition:

$c:$ unit cost

$f:$ Monthly shelf fee

$J_{y}$ : The inventory in Stage $y$, where $y=1,2, \ldots, n$

$\pi:$ Profit

$h$ : Shelf stage of group buying products

$s:$ Inventory quantity

$r$ : Selling price

The online group buying decision model used in this study was derived by referring to the demand function $A_{j y}=L-E J_{y}$, which has been used in inventory-dependent demand studies conducted by scholars in the past [7]. This function is a linear function and was taken as the basic formula for developing the model in this study. Considering that group buying information is often incomplete, grey decision-making was incorporated into the model as the basis for construction. In addition to the inventory quantity, shelf time, and selling price in the online group buying decision model, the changes of other parameters, such as the cost per unit $c$, the monthly shelf cost $f$, and the shelf time of products $h$, was also considered. The shelf cost affects the length of the shelf time of products. The above parameters were all used for the convenience of calculating the revenue of products. Based on the 
above, the profit model of online group buying is equal to the total revenue of selling products minus the cost per unit and the shelf cost per unit time. $\Psi$ is used to express the profit of online group buying. The profit model of online group buying, as derived in this study, is shown in Equation (14) [6-8,29,30]. This decision-making model includes the idea that the samples obtained by the grey correlation analysis do not require a good distribution law, so the amount of calculation required is small, and the results of the quantitative and qualitative analyses are not necessary. The occurrence is a measure of the degree of correlation between factors that vary over time or among different objects. In grey multi-attribute decision making, the choice of most schemes can be considered according to the characteristics of the factors, considering the upper limit effect measure, the lower limit effect measure, and the specific center effect measure $[6,8,26]$

$$
\operatorname{Max} \quad \Psi(r, s, h)=r\left[\left(L-E r-G_{0 i} r\right) \frac{1-\left(1+G_{0 i}\right)^{h}}{1-\left(1+G_{0 i}\right)}\right]-c s-f h
$$

\subsubsection{Inventory Function Deduction}

The initial inventory (Phase- 1 inventory) $J_{1}$ will be equal to the inventory quantity $s$. The Phase-2 inventory $J_{2}$ will be the inventory quantity $s$ minus the Phase- 1 demand $A_{j 1}$, meaning the quantity purchased by customers in Phase 1 ; and the Phase-3 inventory $J_{3}$ will be the Phase-2 inventory $J_{2}$ minus Phase-2 demand $A_{j 2}$. In this way, the inventory function is shown as Equation (15) $[6-8,29,30]$

$$
\begin{gathered}
J_{1}=s \\
J_{2}=s-A_{j 1} \\
J_{3}=s-A_{j 1}-A_{j 2} \\
\cdots \\
J_{y}=s-\sum_{y=1}^{h-1} A_{j y} .
\end{gathered}
$$

\subsubsection{Demand Function Deduction}

We extend the demand function derived by scholars in the past (Sarker et al., 1997) to the basic formula for the development of the demand function used in this study and discuss whether the consumer demand for online group buying will be affected by changes in inventory levels and selling prices. $A_{j}$ is the demand for stage $y_{,} J_{y}$ is the inventory of stage $y, r$ is the selling price, $L$ is the upper limit of the demand, $E$ is the coefficient of influence of the price to demand, $G_{0 i}$ is the marginal decline rate of the demand due to inventory, and $L, E$, and $G_{0 i}$ are all positive constants. $G_{0 i}$ is the marginal decline rate of demand due to inventory. Because the inventory is often affected by many factors, including positive and negative comments from online communities and important factors such as raw material prices and quality impacts, $G_{0 i}$ can consider relevant key factors together to optimize the inventory for online group manufacturers. In addition, when considering the online group manufacturers to make inventory optimization decisions, sometimes the types of information obtained are inconsistent, and when there is a small number of cases, countermeasures still need to be taken.

After the result is deducted, its total demand function is as shown in Equation $(16)[6-8,29,30]$

$$
A_{j y}=\left(L-E r-G_{0 i} J_{y}\right)
$$

In the case of $E^{*} r=120$, the relationships among $L, G_{0 i}, A_{j y}$, and $J_{y}$, and the $A_{j y}$ of demand increase and the $J_{y}$ inventory of $y$ for the period also increases, but $G_{0 i}$ declines, as shown in Figure 1. 


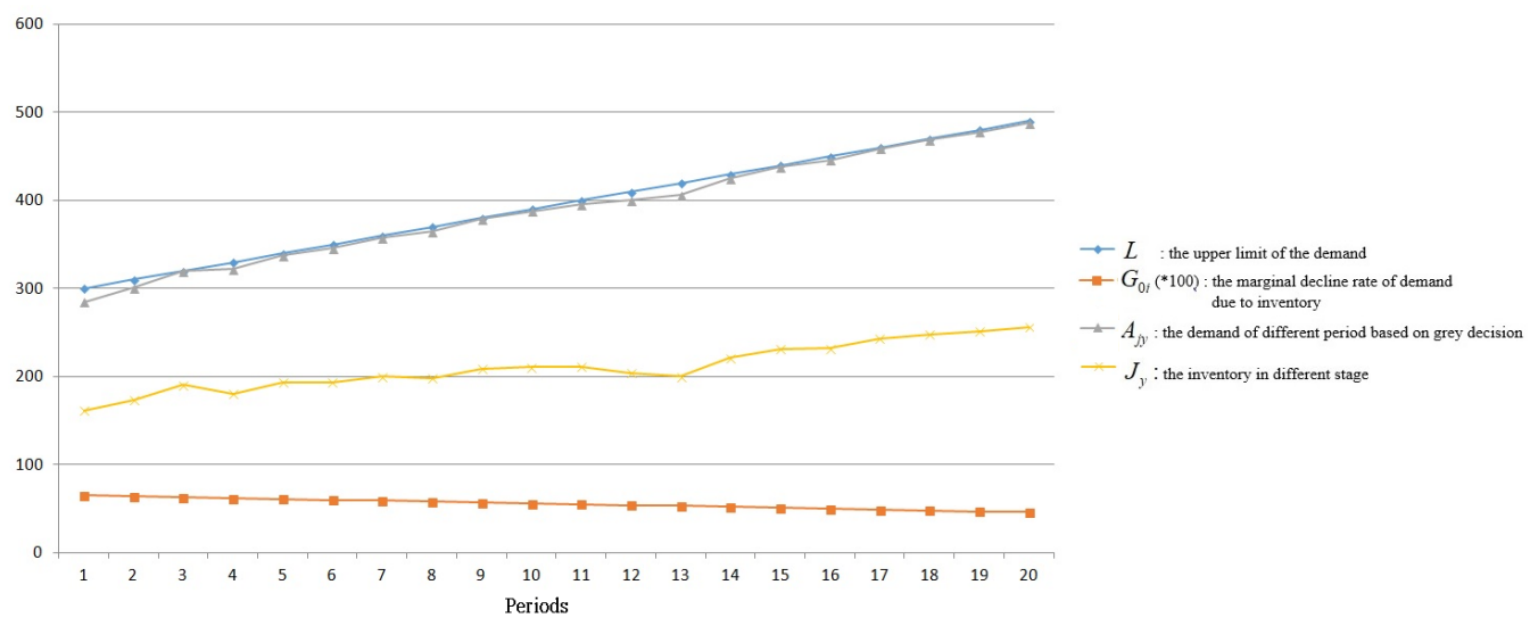

Figure 1. Grey correlation which probably encompasses the marginal utility.

First, the demand-inventory-related function is taken as the first step of derivation, and then, a complete total demand function model is deduced. Assuming that the demand and inventory quantity are inversely related, it can be seen that the first-stage demand of $A_{j 1}$ will be equal to the upper limit of demand $L$, as deduced by the product of the price-to-demand impact coefficient $E$ and the selling price $s$ minus the product of the marginal decline rate of the demand due to the inventory $G_{0 i}$ and inventory quantity $s$. When the inventory quantity and selling price both decrease, the demand will increase; on the contrary, when the inventory quantity and selling price increase, the demand will decrease. Then, the general demand function is deduced by mathematical induction.

Deduction process of the demand function (Appendix A) $[6-8,29,30]$ :

Theorem 1. The demand for commodities in stage y can be determined by deductions, such as that shown in Equation (17) $[6-8,29,30]$ :

$$
A_{j y}=\left(L-E r-G_{0 i} s\right) \times\left(1+G_{0 i}\right)^{y-1} .
$$

Proof. When $A_{j 1}$ is consistent with the formula, the following formula is established:

$$
\begin{gathered}
A_{j 1}=\left(L-E r-G_{0 i s}\right) \times\left(1+G_{0 i}\right)^{1-1} \\
=\left(L-E r-G_{0 i} s\right)
\end{gathered}
$$

If every $k \in N$, the next step will be to prove whether $A_{j k}$ is true; $A_{j k+1}$ is also true, as shown below (Appendix B) $[6-8,29,30]$ :

Theorem 2. The cumulative demand function from Phase 1 to Phase $y$ is shown in Equation (18) [6-8,29,30]:

$$
\sum_{y=1}^{h} A_{j y}=\left(L-E r-G_{0 i} s\right) \frac{1-\left(1+G_{0 i}\right)^{h}}{1-\left(1+G_{0 i}\right)} .
$$

From the derivation of the demand function, we can see that $A_{j 1} \sim A_{j y}$ is a geometric progression. Since the accumulated demand is the accumulated value of the geometric progression, we can obtain the accumulated demand function from Phase 1 to Phase $h$ by applying the formula of geometric progression $[6-8,29,30]$. 


\subsection{Constructing the Profit Function of Online Group Buying}

This study aims to develop a decision model for online group buying. The objective function $(\Psi)$ is obtained by deducting the cost per unit and the shelf cost of the product from the revenue of the overall sales quantity. The total revenue from selling the product is obtained by multiplying the sales price per unit by the sum of demand $\sum_{y=1}^{h} A_{j y}$. The unit cost to be paid for the product is determined by subtracting the product with unit $\operatorname{cost} c$ and inventory quantity $s$. Then, it is subtracted from the product of the shelf cost per unit time $f$ and the shelf period $h$, that is, the cost required for the product to be sold on the shelves. Assuming that there is no shortage in the online group buying in this study, the inventory quantity will definitely be greater than or equal to the total demand. From the above description, we obtain the decision model for online group buying, as shown in Equation (19) $[6-8,29,30]$

$$
\begin{gathered}
\text { Max } \Psi(r, s, h)=r \sum_{y=1}^{h} A_{j y}-c s^{*}-f h \\
=r\left[\left(L-E r-G_{0 i} s\right) \frac{1-\left(1+G_{0 i}\right)^{h}}{1-\left(1+G_{0 i}\right)}\right]-c s^{*}-f h \\
L>E>0 \\
L>r E \\
r, s, h \geq 0
\end{gathered}
$$

\subsection{Analysis of the Optimal Shelf Time for Online Group Buying}

Based on the decision model for online group buying, as constructed above, this study further discusses whether there is a certain degree of difference in the profit of online group buying under the consideration of different parameters, as determined through the partial differential method, and uses the model to discuss whether the inventory quantity $s$, shelf time $h$, and selling price $r$ will bring profit growth to the decision model for online group buying. Furthermore, the optimal formula solution of the decision model for online group buying is derived $[6-8,29,30]$.

Analysis of optimal profit model for online group buying for

Theorem 3 ([6-8,29,30]). The general formula of $s$ is further derived from the restriction formula $s \geq \sum_{y=1}^{h} A_{j y}$ and it is assumed that the inventory quantity will be equal to the total demand under optimal conditions, as shown in Equation (20):

$$
s^{*}=\sum_{y=1}^{h} A_{j y}
$$

Theorem 4. The optimal inventory quantity $s^{*}$ is shown in Equation (21) $[6-8,29,30]$ :

$$
s^{*}=\frac{(L-E r)\left(1+G_{0 i}\right)^{-h}\left[-1+\left(1+G_{0 i}\right)^{h}\right]}{G_{0 i}} .
$$


Proof. Based on Theorem 3, this study substitutes the total demand $\sum_{y=1}^{h} A_{j y}$ into formula (20), and the optimal solution for $s^{*}$ is obtained after deduction, as shown in Equation (22):

$$
\begin{gathered}
s^{*}=\left(L-E r-G_{0 i} s\right) \times\left[\frac{1-\left(1+G_{0 i}\right)^{h}}{1-\left(1+G_{0 i}\right)}\right] \\
{\left[1-\left(1+G_{0 i}\right)\right] s^{*}+G_{0 i}\left[1-\left(1+G_{0 i}\right)^{h}\right] s^{*}=(L-E r)\left[1-\left(1+G_{0 i}\right)^{h}\right]} \\
s^{*}=\frac{(L-E r)\left(1+G_{0 i}\right)^{-h}\left[-1+\left(1+G_{0 i}\right)^{h}\right]}{G_{0 i}}
\end{gathered}
$$

The optimal solution of the inventory quantity $s^{*}$ is substituted into the target formula Max: in the target formula: $r, h$.

$\operatorname{Max} \Psi\left(r, s^{*}, h\right)=r\left[\left(L-E r-G_{0 i} s\right) \times \frac{1-\left(1+G_{0 i}\right)^{t}}{1-\left(1+G_{0 i}\right)}\right]-c s^{*}-f h$, which leaves two decision variables

$s^{*}$ is substituted into the formula

$$
\begin{gathered}
\Psi\left(r, s^{*}, h\right)=-\frac{c(L-E r)\left(1+G_{0 i}\right)^{-h}\left[-1+\left(1+G_{0 i}\right)^{h}\right]}{G_{0 i}} \\
-\frac{r\left[1-\left(1+G_{0 i}\right)^{t}\right]\left\{L-E r-(L-E r)\left(1+G_{0 i}\right)^{-h[}\left[-1+\left(1+G_{0 i}\right)^{h}\right]\right\}}{G_{0 i}}-f h \\
G_{0 i}
\end{gathered}
$$

Then, using the first-order partial differential, which is equal to zero, as the necessary condition, and the second-order partial differential, which is less than zero, as the sufficient condition, the optimal $r^{*}$ and $h^{*}$ values are obtained to maximize $(\Psi)$ in Equation (23). The parameter optimization solution is divided into three parts, as follows: (1) the profit function performs a partial differential function on the shelf time of the commodity to determine the optimal value; (2) the profit function performs a partial differential function on the selling price of the commodity to determine the optimal selling price; and (3) the profit function performs a partial differential function on the shelf time and selling price and detects whether the model satisfies the semi-negative characterization of the function.

\subsection{Verification Analysis of the Profit Function Regarding the Shelf Time}

The profit function $(\Psi)$ performs first-order partial differentiation on the commodity shelf-time (h), as follows (Appendix C) [6-8,29,30]:

The profit function $\Psi$ performs second-order partial differentiation on the commodity shelf-time $t$, as follows (Appendix D) [6-8,29,30]:

$$
\text { We get it for sure } \frac{\partial^{2} \Psi}{\partial h^{2}}<0 \text {. }
$$

Under the condition that the second-order partial differential of profit is less than zero and can satisfy the optimal shelf-time $(h)$ of commodities, the expected profit can reach the maximum value; thus, this study further deduced the optimal shelf-time of the commodity.

The first-order partial differential is set, as performed by the profit function $(\Psi)$ on the commodity shelf-time $(h)$, to zero.

It is known that the second-order partial differential of this profit function is less than zero. If we let $\frac{\partial \Psi}{\partial h}=0$, the optimal solution of shelf-time can be obtained by solving this equation, as shown in Equation (24):

$$
h^{*}=\frac{\log \left[\frac{\left(L c-L r-E c r+E r^{2}\right) \log \left(1+G_{0 i}\right)}{f G_{0 i}}\right]}{\log \left(1+G_{0 i}\right)} .
$$


The profit function $(\Psi)$ is used to perform first-order partial differentiation on the shelf-time $(h)$ of the commodity, and the formula of the first-order partial differentiation is set to zero in order to obtain the optimal shelf period $\left(h^{*}\right)$ through which online group buying can be used to maximize profit.

\subsubsection{Verification Analysis of Profit Function Regarding Selling Price}

The profit function $(\Psi)$ performs first-order partial differentiation on the selling price $(r)$, as shown in Equation (25)

$$
\begin{gathered}
\frac{\partial \Psi}{\partial r}=\frac{\left(1+G_{0 i}\right)^{h}\left\{L\left[-1+\left(1+G_{0 i}\right)^{h}\right]+E\left[(c-r)\left(-1+\left(1+G_{0 i}\right)^{h}\right)-E r\left(-1+\left(1+G_{0 i}\right)^{h}\right)\right]\right\}}{G_{0 i}} \\
=\frac{[L+E c-2 E r]\left(1+G_{0 i}\right)^{-h}\left[-1+\left(1+G_{0 i}\right)^{h}\right]}{G_{0 i}}
\end{gathered}
$$

The second-order partial differential of the profit function $(\Psi)$ to the selling price $(r)$ is

$$
\begin{gathered}
\frac{\partial^{2} \Psi}{\partial r^{2}}=-\frac{2 E\left(1+G_{0 i}\right)^{-h}\left[-1+\left(1+G_{0 i}\right)^{h}\right]}{G_{0 i}}<0 . \\
\text { We get it for sure } \frac{\partial^{2} \Psi}{\partial r^{2}}<0 .
\end{gathered}
$$

The first-order partial differential of the profit function $(\Psi)$ on the selling price $(r)(\mathrm{NT} \$)$ is set to be equal to zero. Knowing that the second-order partial differential of the profit function is less than zero and $\frac{\partial \Psi}{\partial r}=0$, the optimal solution of the selling price can be obtained by solving this equation, as shown in Equation (26):

$$
r^{*}=\frac{L+E c}{2 E} .
$$

By running first-order partial differentiation of the profit function $(\Psi)$ on the selling price $(r)$, we can see that the selling price and the profit have a reverse relationship, that is, when the selling price rises, the commodity cost will also rise, and the expected profit performance will decrease, and this phenomenon is in line with the actual situation. Then, the expression of the first-order partial differentiation is set to be equal to zero in order to determine the optimal shelf life $h^{*}$ through which Internet group buying can maximize its profit.

\subsubsection{Semi-Negative Qualitative Verification of the Profit Function}

The profit function $(\Psi)$ differentiates between the period when the products are put on shelves $(h)$ and the selling price $(r)$, as shown below (Appendix E) $[6-8,29,30]$ it can be seen that

$$
\frac{\partial^{2} \Psi}{\partial h \partial r} \leq 0
$$

In the above partial differential process, the first-order partial differential is equal to zero, and the second-order partial differential is less than zero. It can be understood that the profit function in this study is a convex upward function, meaning that this model has a unimodal structure, and the maximum value of the profit function can be found.

Based on $\left(\frac{\partial^{2} \Psi}{\partial r^{2}}\right)\left(\frac{\partial^{2} \Psi}{\partial h^{2}}\right)-\left(\frac{\partial^{2} \Psi}{\partial h \partial r}\right)^{2} \geq 0$, the profit function is tested to determine whether it satisfies semi-negative qualification, as

$$
\frac{\left(1+G_{0 i}\right)^{-2 h}\{-[L+E c-2 E r]\}^{2}+(2 E c-2 E r)(-L+E r)\left[-1+\left(1+G_{0 i}\right)^{h}\right]\left[\log \left(1+G_{0 i}\right)\right]^{2}}{\left(G_{0 i}\right)^{2}}>0
$$


The above formulas show that when $\frac{\partial \Psi}{\partial h}=0$ and $\frac{\partial \Psi}{\partial r}=0$ and $\left(\frac{\partial^{2} \Psi}{\partial r^{2}}\right)\left(\frac{\partial^{2} \Psi}{\partial h^{2}}\right)-\left(\frac{\partial^{2} \Psi}{\partial h \partial r}\right)^{2} \geq 0$ is satisfied, the profit function has a relative maximum, which also satisfies the semi-negative characterization of the profit function.

\subsection{Optimal Inventory Quantity}

The incentives for the development of Taichung City (Taiwan) are mostly related to the consumption-type service industry. The attracted consumer population is also dominated by the central region. The service industry's population accounts for the absolute majority of the total employment population, and the service industry needs to have a fairly high level of knowledge. Therefore, many of the migrants attracted by Taichung City are those who have received upper-middle education, and they have lost the flow of traffickers. Therefore, they have formed an emerging white-collar class. These emerging white-collar workers have considerable educational standards and experience in the industries in which they work. They are mostly based in the service industry. The number of office workers in online group buying is also quite significant $[2,10]$.

This case study used the general office workers as the research object. Because of the consideration of the feasibility factors, the study was based on the second largest city in Taiwan. The study explored the behaviors related to office group purchases, so it was locked in the service industry where office workers are the mainstay. Based on the "Statistical Data of the Human Resources Statistics Annual Report of the Executive Office of the Executive Yuan in the Republic of China in 106 years", the researchers randomly selected the sample size by means of stratified proportional sampling. The numbers of samples for each service category are shown in Table 1 . The online questionnaire was distributed according to the number of sample samples in Table 1. After validating the questionnaire through pre-testing of the revised questionnaire, 20 formal questionnaires were issued, and after the invalid questionnaires were deleted, there was be a total of 420 valid questionnaires. Therefore, approximately 21 valid questionnaires (stratified sampling) were received in each period. The formula for estimating the finite population of the second largest city in Taiwan is $n=\frac{N}{N\left(\frac{2 d}{Z_{\frac{\alpha}{2}}}\right)^{2}+1}$, where the number of population bodies is known to be 559,000 with a $95 \%$ confidence level, and the number of samples is at least $384[2,10]$. Table 1 shows the estimated number of urban workers in the second largest city in Taiwan.

Table 1. Estimated number of urban workers in the second largest city in Taiwan

\begin{tabular}{ccc}
\hline Service Category & $\begin{array}{c}\text { Number of Population } \\
\text { Bodies (Unit: Thousands } \\
\text { of People) }\end{array}$ & $\begin{array}{c}\text { Estimated Number of } \\
\text { Official Samples Taken } \\
\text { (Unit: PEOPLE) }\end{array}$ \\
\hline Wholesale and retail trade & 219 & 150 \\
Accommodation and catering industry & 89 & 61 \\
Finance and insurance & 45 & 31 \\
Professional, scientific, and technical service industry & 45 & 31 \\
Government employee & 108 & 74 \\
Healthcare and social work services & 53 & 36 \\
Total & 559 & 384 \\
\hline
\end{tabular}

\section{Discussion}

To speed up dispatching, group buying websites gather a large number of consumers with a large purchase amount $(L)$ to accelerate the dispatching speed of merchants, reduce the inventory cost of manufacturers, improve the inventory turnover speed, and speed up the return of funds. The main purpose of group buying is to bargain with manufacturers to achieve more favorable purchasing conditions by gathering the strength of multiple consumers, while manufacturers can benefit from reducing excess inventory. The number of people currently participating in group buying will affect the decisions of potential consumers regarding whether or not to participate in group buying. Based 
on Equation (22), when the number of people participating in group buying is greater, consumers can bargain through large-scale purchases. By controlling prices through quantity, the effect of the decline in consumers' expected price $\left(G_{0 i}\right)$ will increase accordingly. Consumers can buy products at a lower price, thus, encouraging more consumers to join group buying schemes. In this study, $L=300, E=08$, $r=150, G_{0 i}=0.65$, and $\mathrm{h}($ day $)=30$ were taken as the initial values. When $L$ gradually increased, it led to a trend in the gradual decrease of $G_{0 i}$ and a gradual increase in $s^{*}$. In the first three phases, $s<\sum_{y=1}^{h} A_{j y}$, and due to the high level of $G_{0 i}$, the inventory quantity was less than the total demand, as shown in Figure 2. Table 2 shows the TOPSIS analysis of parameters used in this study.

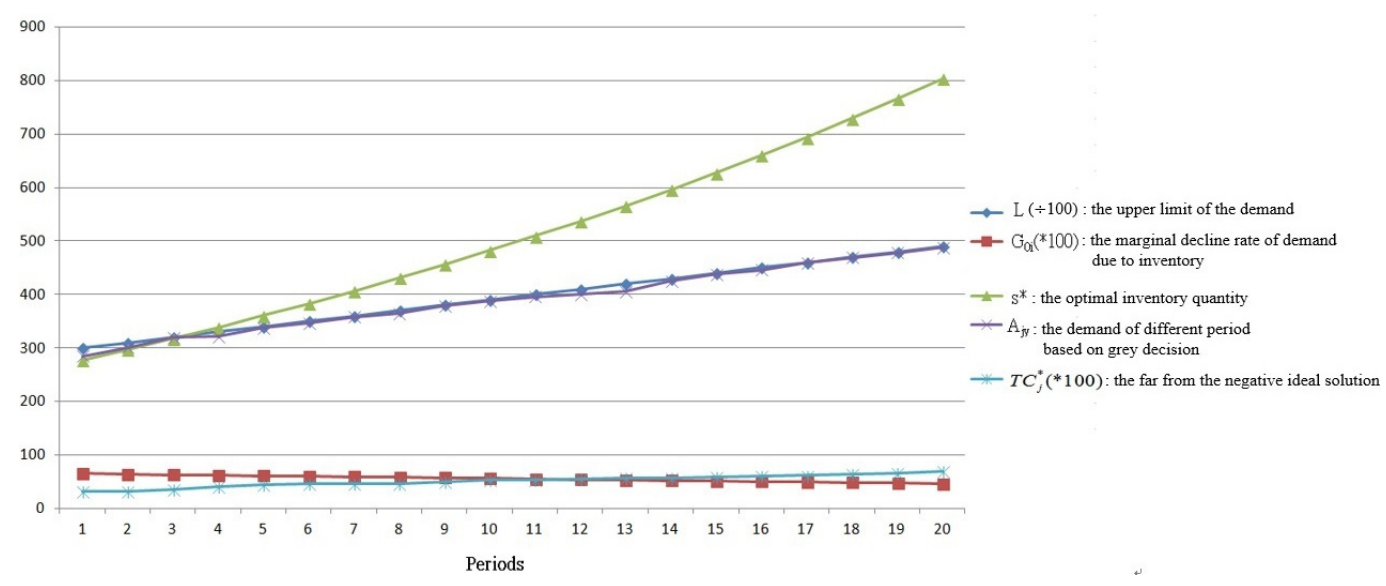

Figure 2. Influence of relevant parameters on the optimal inventory quantity.

Table 2. TOPSIS (technique for order preference by similarity to ideal solution) analysis of parameters in this study

\begin{tabular}{cccc}
\hline Periods & $\boldsymbol{K}_{j}^{*}$ & $\boldsymbol{K}_{j}^{-}$ & $\left.\boldsymbol{T} \boldsymbol{C}_{j}^{*}{ }^{*}{ }^{*} 100\right)$ \\
\hline 1 & 0.26 & 0.12 & 32 \\
2 & 0.38 & 0.18 & 32 \\
3 & 0.39 & 0.21 & 35 \\
4 & 0.4 & 0.28 & 41 \\
5 & 0.41 & 0.33 & 45 \\
6 & 0.42 & 0.36 & 46 \\
7 & 0.53 & 0.46 & 46 \\
8 & 0.67 & 0.58 & 46 \\
9 & 0.78 & 0.78 & 50 \\
10 & 0.7 & 0.8 & 53 \\
11 & 0.7 & 0.81 & 54 \\
12 & 0.68 & 0.85 & 56 \\
13 & 0.66 & 0.88 & 57 \\
14 & 0.67 & 0.9 & 57 \\
15 & 0.63 & 0.92 & 59 \\
16 & 0.6 & 0.93 & 61 \\
17 & 0.5 & 0.8 & 62 \\
18 & 0.48 & 0.85 & 64 \\
19 & 0.46 & 0.87 & 65 \\
20 & 0.4 & 0.93 & 70 \\
\hline
\end{tabular}

Group buying is convenient, but there are still risks. For example, the analysis in Figure 2 is valuable because the quantity of inventory is shown to be insufficient and the waiting time is too long. This study finds that the potential consumer group's Internet frequency is similar to that of the target consumer group, and the disposable amount is more than that of the target consumer group. It is important to determine which group buying platforms the target consumer group has used and to 
analyze their consumption behavior preferences and purchasing needs as this provides a reference to the store that can be used to choose the shelves of merchandise in the group buying platform, and finally, to provide specific methods for each group buying platform to enhance or strengthen the competitive advantage [1], as shown in Figure 3.

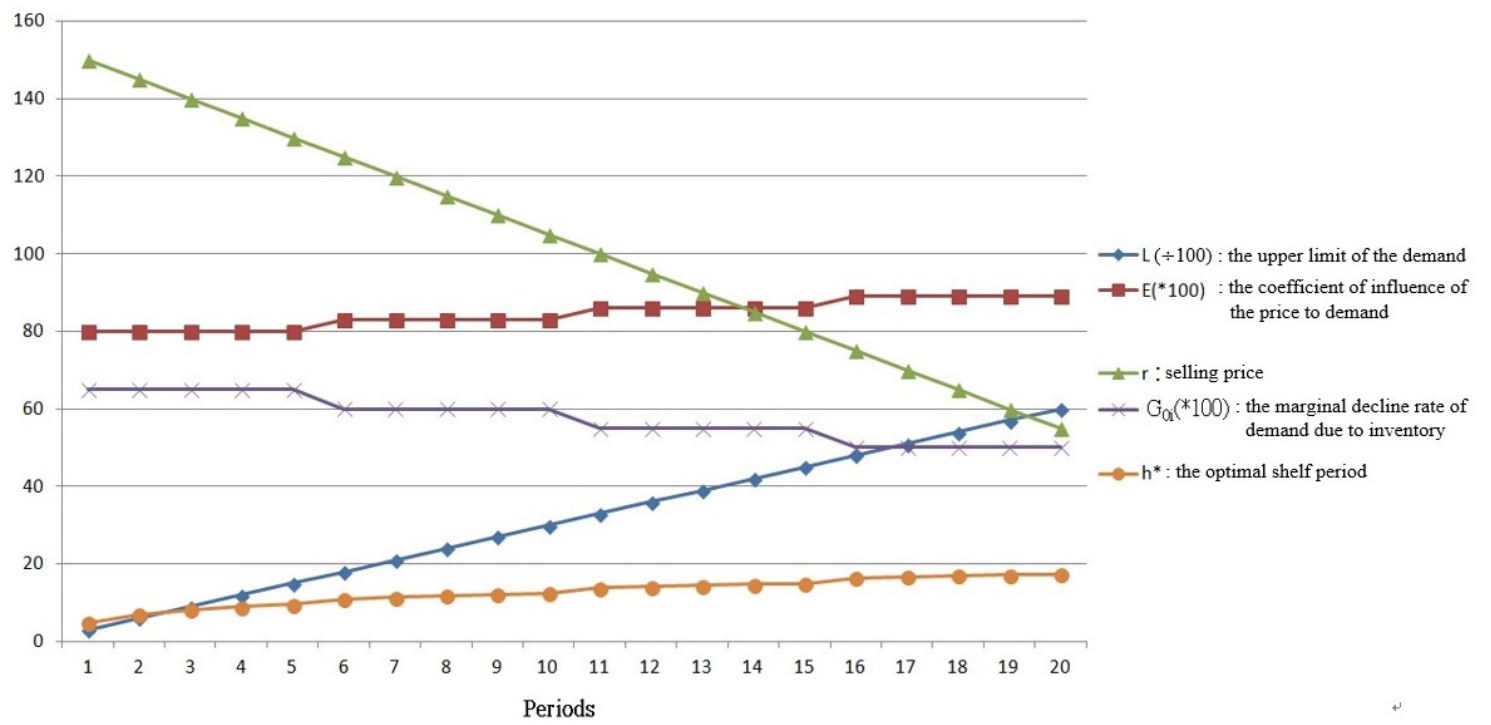

Figure 3. Influence of relevant parameters on commodity shelf-time.

\subsection{Commodity Shelf-Time}

Group buying websites have power because they have a loyal customer base that wants bargains and their own marketing resources. A product was once sold to nearly 2000 groups in one month on a famous group buying website. However, the disadvantage is that after a group buying website is introduced, it is very difficult to sell products at the original price, because even after the end of the offer, customers can still find the historical price records on group buying websites (consumers usually have an expectation psychology). This forms the mentality that consumers are always waiting for anniversary discounts. According to Equation (24) and the estimation of business parameters, $c$ is 200, $f$ is $600, r$ decreases, $G_{0 i}$ decreases, $E$ increases, and $L$ increases. It is estimated that 13 to 15 days is the best shelf-time (rounding method), because the reasonable selling price of any manufacturer is NT $\$ 80$ to NT\$105, as shown in Figure 3.

\subsection{Selling Price of Online-Group-Buying Products}

According to Equation (26), relevant parameters are based on the data provided by merchant interviews. The price discount offered by group buying websites is similar to the wholesale price, which obviously enables consumers to enjoy greater benefits and reduce the shopping costs of consumers $(c$ decreases). According to a study by Kenney [31], the reason why customers can save money when shopping online mainly lies in the savings of product costs and shopping browsing costs. In terms of the product cost, the operation of online shops enables manufacturers to save shop setup and inventory costs ( $L$ decreases). Some cost savings may be reflected in the selling price, thus enabling customers to obtain products at a lower price ( $E$ decreases), as shown in Figure 4. 


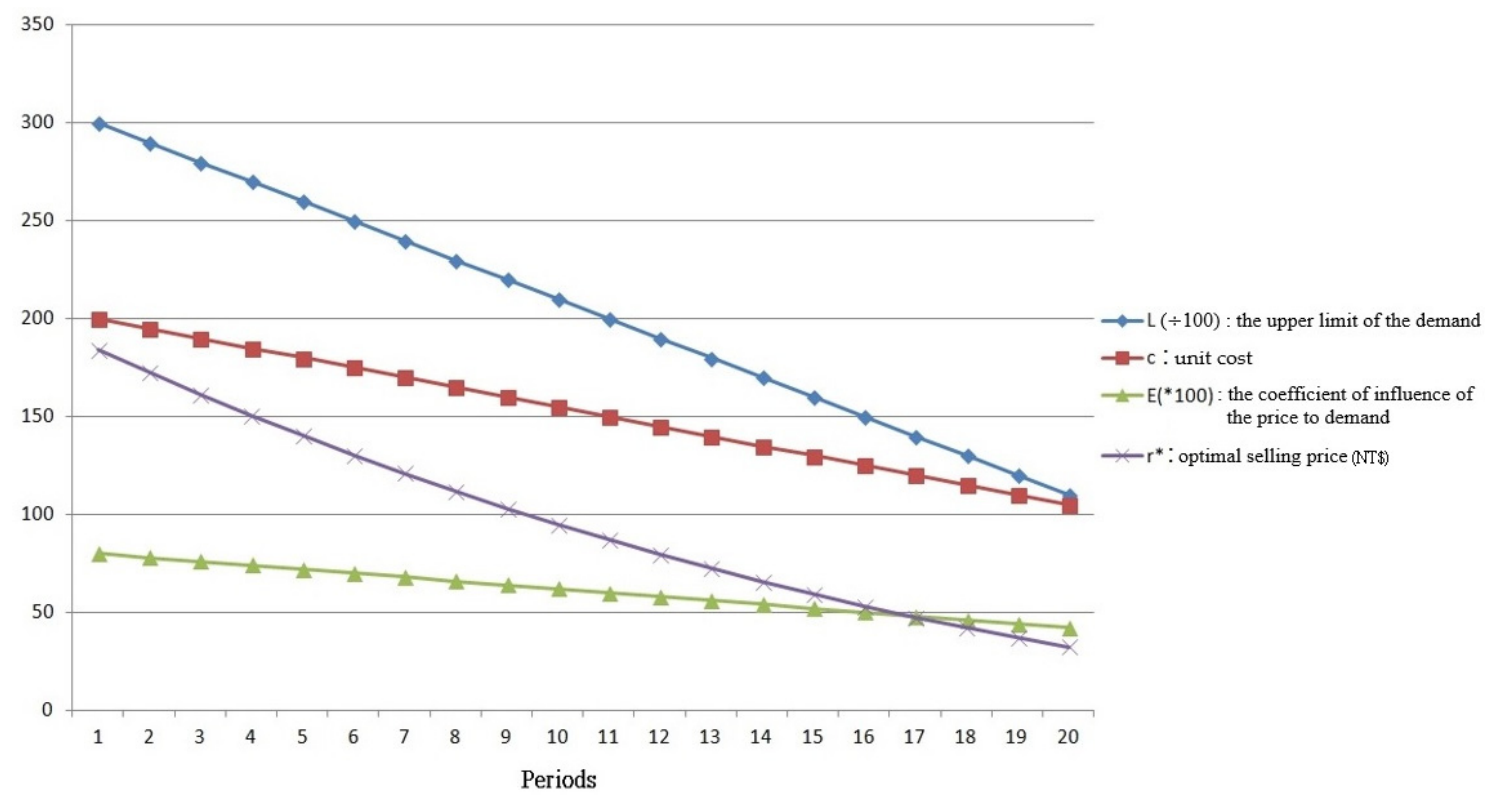

Figure 4. Influence of relevant parameters on the selling price of online group purchases.

Based on Equation (17), $L$ can be derived as shown in Equation (27)

$$
L=\frac{A_{j y}}{\left(1+G_{0 i}\right)^{y-1}}+G_{0 i}(E+s)
$$

Based on the above Equation (27). The upper limit of the demand $(L)$ be given total demand function $\left(A_{j y}\right)$, the marginal decline rate of the demand due to inventory $\left(G_{0 i}\right)$ and inventory quantity (s) of effect. If the sales of online products are not as expected, it will decreased in $L$, decreased in $A_{j y}$, decreased in $s$, and risen in $G_{0 i}$, so that the selling price Equation(26) $(r)$ will decreased. As shown in the Figure 5.

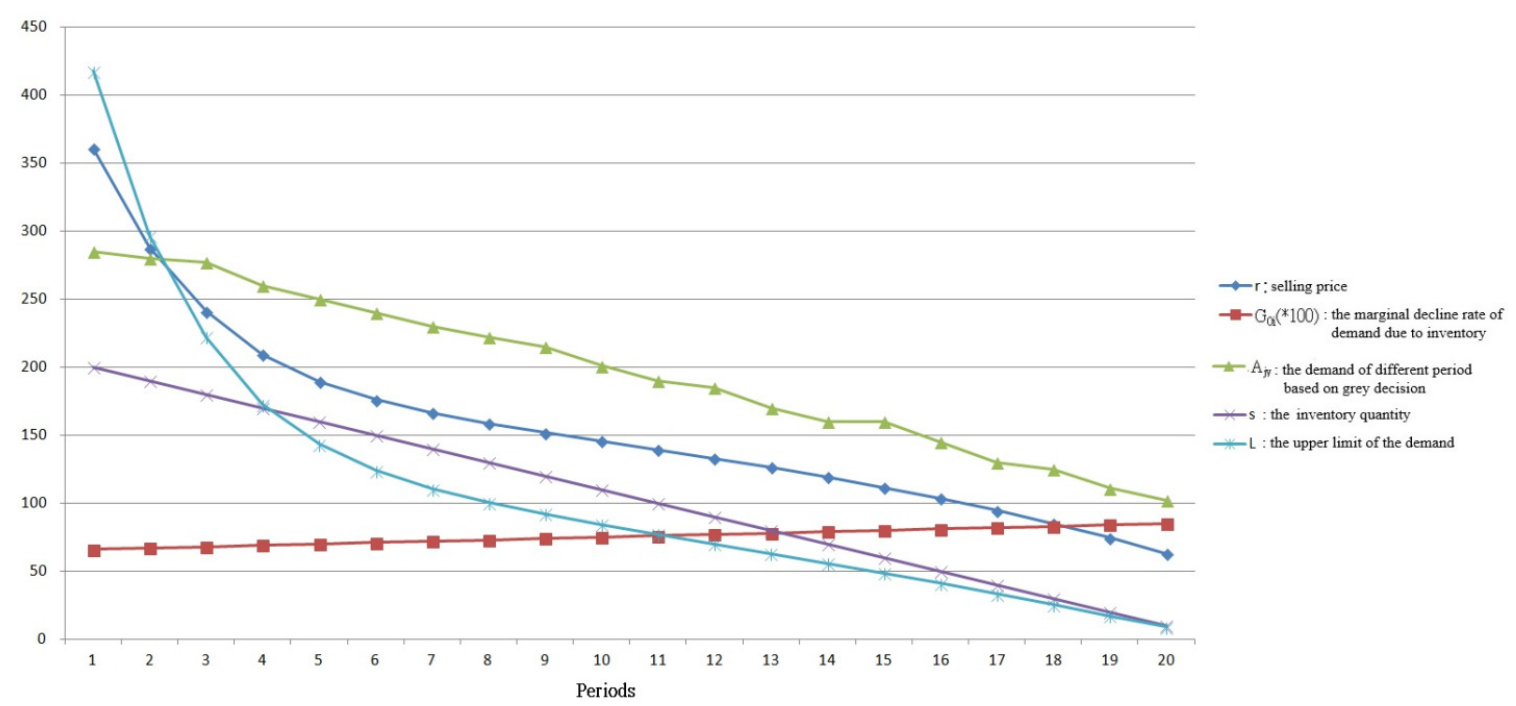

Figure 5. Upper limit of the demand $(L)$ and related parameters of relationship.

Deng et al. [10] have provided useful advice to operators of group buying websites on how to encourage sellers to offer substantial discounts. Lu et al. [2] used a regression analysis to test the relationship between group buying behavior and workplace relationships and found that workplace group buying behavior has a positive correlation with workplace relationship opportunities and 
workplace relationship quality. Different studies [2,10] have shown that the number of people currently participating in group buying affects the decision of potential consumers regarding whether or not to participate in group buying. Based on Equation (22), when the number of people participating in group buying is greater, consumers can bargain through large-scale purchases. The disadvantage is that after a group buying website is introduced, it is very difficult to sell products at the original price, because even after the end of the offer, customers can still find the historical price records on group buying websites (consumers usually have an expectation psychology). This forms the mentality that consumers are always waiting for anniversary discounts. According to Equation (26), relevant parameters are based on the data provided by merchant interviews. The price discount offered by group buying websites is similar to the wholesale price, which obviously enables consumers to enjoy greater benefits and reduce the shopping costs of consumers ( $c$ decreases).

\section{Conclusions}

This study considered the marginal decline rate of the inventory-dependent demand $G_{0 i}$, the upper limit of demand $L$, and other parameters which affect the inventory quantity of group buying operators. This study focused on the selling price of online group purchases and considered various parameters, such as the upper limit of demand $L$, the unit $\operatorname{cost} c$, the influence coefficient of the price on demand $E$, etc. This study used the grey correlation ranking method and grey multi-attribute decision-making (TOPSIS) to further determine the optimal shelf-time, inventory quantity, and selling price (key parameters) of commodities in order to design a plan that makes the maximum profit for the industry and provides the best service to customers [6-12]. In previous studies, $\mathrm{Ni}$ et al. [9], considered the optimal fixed-price decisions, Deng et al. [10] considered the optimal price and maximum deal size, and Lu et al. [2] considered effect of behavior on workplace relationships in online group purchasing.

The seller must have a reservation price which cannot be below a given threshold, and that threshold goes downward as the time goes by, becoming less and less depending on the acquisition price of that product. In particular, many group purchases are perishable products, for which this phenomenon is even greater [1,10].

Group buying websites gather a large number of consumers with large purchase amounts, which can speed up the dispatching speed of merchants so that they can quickly sell products, allowing funds to be returned, reducing the inventory costs of manufacturers, and improving the turnover speed of the inventory. The main purpose of group buying is to bargain with manufacturers to achieve more favorable purchase conditions by increasing the strength of consumers. Manufacturers can also benefit from reducing excess inventory helping them to more accurately master key production parameters at the right price, commodity shelf-time, and inventory. The results of this study can help Internet group buying operators and customers to obtain the best win-win decisions. The limitations of the current study are that only the grey theory was considered to determine the correct price of the manufacturer, the time of stocking, and the quantity of stock. In addition, the sample considered was from Taichung City (Taiwan), where the number of office workers included in online groups is quite significant. In the future, relevant quantity estimation mathematical models can be applied to different online group buying business models.

Author Contributions: S.-T.W. provided the integrated research method, data analysis and creative concept for this research. M.-H.L. provided the references discuss for this research. C.-C.L. provided the content of integrated for this research.

Funding: This research received no external funding.

Conflicts of Interest: The authors declare no conflicts of interest. 


\section{Appendix A}

Deduction process of demand function:

$$
\begin{gathered}
A_{j 1}=L-E r-G_{0 i} J_{1} \\
=L-E r-G_{0 i} s \\
A_{j 2}=L-E r-G_{0 i} J_{2} \\
=L-E r-G_{0 i}\left[s-\left(L-E r+G_{0 i} s\right)\right] \\
=L-E r-G_{0 i} s-G_{0 i} L-G_{0 i} E r+\left(G_{0 i}\right)^{2} s \\
=\left(1+G_{0 i}\right)\left[(L-E r)-G_{0 i} s\right] \\
A_{j 3}=L-E r-G_{0 i} J_{3} \\
=L-E r-G_{0 i}\left(s-A_{j 1}-A_{j 2}\right) \\
=L-E r-G_{0 i} s+2 G_{0 i} L-2 G_{0 i} E r-2\left(G_{0 i}\right)^{2} s-\left(G_{0 i}\right)^{2} E r+\left(G_{0 i}\right)^{2} L-\left(G_{0 i}\right)^{3} s \\
=\left(1+G_{0 i}\right)^{2}\left(L-E r+G_{0 i} s\right) \\
\quad \ldots \ldots \\
A_{j y}=L-E r-G_{0 i} J_{y} \\
=\left(1+G_{0 i}\right)^{y-1}\left[(L-E r)-G_{0 i} s\right]
\end{gathered}
$$

\section{Appendix B}

Step 1: set $A_{j k}=\left(1+G_{0 i}\right)^{j k-1} \times\left(L-E r-G_{0 i} s\right)$

Step 2:

$$
\begin{gathered}
A_{j k+1}=\left(L-E r-G_{0 i} J_{k}\right) \\
=L-E r-G_{0 i}\left(s-\sum_{y=1}^{k} A_{j y}\right) \\
=L-E r-G_{0 i}\left[s-\left(L-E r-G_{0 i} s\right) \times \frac{1-\left(1+G_{0 i}\right)^{k}}{1-\left(1+G_{0 i}\right)}\right] \\
=\left(L-E r-G_{0 i} s\right)\left[1+G_{0 i} \frac{1-\left(1+G_{0 i}\right)^{k}}{1-\left(1+G_{0 i}\right)}\right] \\
=\left(L-E r-G_{0 i} s\right)\left\{\frac{1-\left(1+G_{0 i}\right)+G_{0 i}\left[1-\left(1+G_{0 i}\right)^{k}\right]}{1-\left(1+G_{0 i}\right)}\right\} \\
=\left(L-E r-G_{0 i} s\right)\left\{\frac{-G_{0 i}+G_{0 i}\left[1-\left(1+G_{0 i}\right)^{k}\right]}{1-\left(1+G_{0 i}\right)}\right\} \\
=\left(L-E r-G_{0 i} s\right)\left[\frac{-G_{0 i}\left(1+G_{0 i}\right)^{k}}{-G_{0 i}}\right] \\
=\left(L-E r-G_{0 i} s\right)\left(1+G_{0 i}\right)^{k}
\end{gathered}
$$

From above we can know:

$$
\begin{aligned}
A_{j k+1} & =\left(L-E r-G_{0 i s} s\right)\left(1+G_{0 i}\right)^{k+1-1} \\
& =\left(L-E r-G_{0 i} s\right)\left(1+G_{0 i}\right)^{k}
\end{aligned}
$$

\section{Appendix C}

$$
\begin{gathered}
\frac{\partial \Psi}{\partial t}=-\frac{\left(1+G_{0 i}\right)^{-h}\left\{-L-c+r\left[-1+\left(1+G_{0 i}\right)^{h}\right]+E(c-r) r\left[-1+\left(1+G_{0 i}\right)^{h}\right]-f h G_{0 i}\left(1+G_{0 i}\right)^{h}\right\}}{G_{0 i}} \\
+\frac{\log \left(1+G_{0 i}\right)\left(1+G_{0 i}\right)^{-h}\left[-f G_{0 i}\left(1+G_{0 i}\right)^{h}-L(c-r)\left(1+G_{0 i}\right)^{h} \log \left(1+G_{0 i}\right)+E(c-r) r\left(1+G_{0 i}\right)^{h}\right.}{G_{0 i}} \\
-\frac{\left.\log \left(1+G_{0 i}\right)-f h G_{0 i}\left(1+G_{0 i}\right)^{h} \log \left(1+G_{0 i}\right)\right]}{G_{0 i}} \\
=\frac{\left(1+G_{0 i}\right)^{-h}\left[-f G_{0 i}\left(1+G_{0 i}\right)^{h}+(c-r)(-L+E r) \log \left(1+G_{0 i}\right)\right]}{G_{0 i}}
\end{gathered}
$$




\section{Appendix D}

$$
\begin{gathered}
\frac{\partial^{2} \Psi}{\partial h^{2}}=-\frac{\left(1+G_{0 i}\right)^{-h}\left\{-L(c-r)\left[-1+\left(1+G_{0 i}\right)^{h}\right]+E(c-r) r\left[-1+\left(1+G_{0 i}\right)^{h}\right]-f G_{0 i}\left(1+G_{0 i}\right)^{h} h\right\} \log \left(1+G_{0 i}\right)^{2}}{G_{0 i}} \\
-\frac{2\left(1+G_{0 i}\right)^{-h} \log \left(1+G_{0 i}\right)\left[-f G_{0 i}\left(1+G_{0 i}\right)^{h}-L(c-r)\left(1+G_{0 i}\right)^{h} \log \left(1+G_{0 i}\right)-f G_{0 i}\left(1+G_{0 i}\right)^{h} h \log \left(1+G_{0 i}\right)\right]}{G_{0 i}} \\
+\frac{\left(1+G_{0 i}\right)^{-h}\left[-2 f G_{0 i}\left(1+G_{0 i}\right)^{h} \log \left(1+G_{0 i}\right)-L(c-r)\left(1+G_{0 i}\right)^{h} \log \left(1+G_{0 i}\right)^{2}+E(c-r) r\left(1+G_{0 i}\right)^{h} \log \left(1+G_{0 i}\right)^{2}\right.}{G_{0 i}} \\
+\frac{\left.E(c-r) r\left(1+G_{0 i}\right)^{h} \log \left(1+G_{0 i}\right)^{2}-f G_{0 i}\left(1+G_{0 i}\right)^{h} h \log \left(1+G_{0 i}\right)^{2}\right]}{G_{0 i}} \\
=\frac{(c-r)(L-E r)\left(1+G_{0 i}\right)^{-h} \log \left(1+G_{0 i}\right)^{2}}{G_{0 i}}<0
\end{gathered}
$$

\section{Appendix E}

$$
\begin{gathered}
\frac{\partial^{2} \Psi}{\partial h \partial r}=\frac{\left(1+G_{0 i}\right)^{-h}\left\{L\left[-1+\left(1+G_{0 i}\right)^{h}\right]+E(c-r)\left[-1+\left(1+G_{0 i}\right)^{h}\right]-E r\left[-1+\left(1+G_{0 i}\right)^{h}\right]\right\} \log \left(1+G_{0 i}\right)}{G_{0 i}} \\
+\frac{\left(1+G_{0 i}\right)^{-h}\left\{L\left[\left(1+G_{0 i}\right)^{h}\right] \log \left(1+G_{0 i}\right)+E c-E r\left(1+G_{0 i}\right)^{h} \log \left(1+G_{0 i}\right)-E r\left(1+G_{0 i}\right)^{h} \log \left(1+G_{0 i}\right)\right\}}{G_{0 i}} \\
=\frac{[L+E c-2 E r]\left(1+G_{0 i}\right)^{-h} \log \left(1+G_{0 i}\right)}{G_{0 i}} \leq 0
\end{gathered}
$$

\section{References}

1. Anand, K.S.; Aron, R. Group Buying on the Web: A Comparison of Price-Discovery Mechanisms. Manag. Sci. 2003, 49, 1546-1562. [CrossRef]

2. Lu, P.J.; Chang, Y.H.; Lin, W.H.; Tai, P.Y.; Yeh, Y.L. Group buying is more than just shopping: Exploring the impact of group buying behavior on workplace friendships. J. Technol. Manpow. Educ. Q. 2019, 5, 117-140.

3. Zhao, M.R. How much does the Group Purchaser Earn in a Month? World Magazine, 8 February 2018.

4. Kauffman, R.J.; Wang, B. New Buyer's Arrival under Dynamic Pricing Market Microstructure: The Case of Group-Buying Discounts on The Internet. J. Manag. Inf. Syst. 2001, 18, 157-188. [CrossRef]

5. Wei, Y.; Straub, D.W.; Poddar, A. The Power of Many: An Assessment of Managing Internet Group Purchasing. J. Electron. Commer. Res. 2011, 12, 19-43.

6. Deng, J.L. Control problems of grey systems. Syst. Control Lett. 1982, 1, 288-294.

7. Sarker, B.R.; Mukherjee, S.; Balan, C.V. An Order-Level Lot Size Inventory Model with Inventory-Level Dependent Demand and Deterioration. Int. J. Prod. Econ. 1997, 48, 227-236. [CrossRef]

8. Chien, C.F. Decision Analysis and Management: A Unison Framework for Total Decision Quality Enhancement; Yeh Yeh Book Gallery: Taipei, Taiwan, 2015.

9. Ni, G.; Xu, Y.; Xu, J.; Dong, Y. Optimal Decisions for Fixed-Price Group-Buying Business Originated in China: A Game Theoretic Perspective. Int. J. Prod. Res. 2015, 53, 2995-3005. [CrossRef]

10. Deng, S.; Jiang, X.; Li, Y. Optimal Price and Maximum Deal Size on Group-Buying Websites for Sellers with Finite Capacity. Int. J. Prod. Res. 2018, 56, 1918-1933. [CrossRef]

11. Barbara, F.; Morgia, V.L.; Parodi, V.; Toscano, G.; Venturino, E. Analysis of the Incidence of Poxvirus on the Dynamics between Red and Grey Squirrels. Mathematics 2018, 6, 113. [CrossRef]

12. Taleizadeh, A.A.; Babaei, M.S.; Sana, S.S.; Sarkar, B. Pricing Decision within an Inventory Model for Complementary and Substitutable Products. Mathematics 2019, 7, 568. [CrossRef]

13. Kauffman, R.J.; Wang, B. Bid Together, Buy Together: On the Efficacy of Group-Buying Business Model in Internet-Based Selling. In Handbook of Electronic Commerce in Business and Society; Lowry, P.B., Cherrington, J.O., Watson, R.R., Eds.; CRC Press: Baca Raton, FL, USA, 2002.

14. Liaw, G.F.; Zhu, Z.W.; Lee, Y.H. The effects of risk reduction strategies on consumers' risk perceptions and online purchase intention. Pan-Pac. Manag. Rev. 2005, 8, 1-37.

15. Chen, J.; Chen, X.; Song, X. Bidder's strategy under group-buying auction on the Internet. IEEE Trans. Syst. Man Cybern. Part A Syst. Hum. 2002, 32, 680-690. [CrossRef]

16. Kozinets, R.V. The Field behind the Screen: Using Netnography for Marketing Research in Online Communications. J. Mark. Res. 2002, 39, 61-73. [CrossRef] 
17. Arnould, E.; Price, L.; Zinkhan, G. Consumers, 2nd ed.; McGraw Hill Higher Education: New York, NY, USA, 2003.

18. Kumar, V.; Rajan, B. Social Coupon as a Marketing Strategy: A Multifaceted Perspective. J. Acad. Mark. Sci. 2012, 40, 120-136. [CrossRef]

19. Sahay, A. How to Reap Higher Profits with Dynamic Pricing. MIT Sloan Manag. Rev. 2007, 48, 53-60.

20. Kahneman, D.; Knetsch, J.L.; Thaler, R.H. Fairness and the assumptions of economics. J. Bus. 1986, 59, 285-300. [CrossRef]

21. Kalapurakal, R.; Dickson, P.R.; Urbany, J.E. Perceived price fairness and dual entitlement. Adv. Consum. Res. 1991, 18, 788-793.

22. Oliver, R.L.; Swan, J.E. Consumer Perceptions of Interpersonal Equity and Satisfaction in Transactions: A Field Survey Approach. J. Mark. 1989, 53, 21-35. [CrossRef]

23. Chen, J.; Kauffman, R.J.; Liu, Y.; Song, X. Segmenting uncertain demand in group-buying auctions. Electron. Commer. Res. Appl. 2010, 9, 126-147. [CrossRef]

24. Kauffman, R.J.; Lai, H.; Ho, C.T. Incentive mechanisms, fairness and participation in online group-buying auctions. Electron. Commer. Res. Appl. 2010, 9, 249-262. [CrossRef]

25. Yan, R.N.; Lotz, S. The Waiting Game: The Role of Predicted Value, Wait Disconfirmation, and Providers' Actions in Consumers' Service Evaluations. Adv. Consum. Res. 2006, 33, 412-418.

26. Golmohammadi, D.; Mellat-Parast, M. Developing a grey-based decision-making model for supplier selection. Int. J. Prod. Econ. 2012, 137, 191-200. [CrossRef]

27. Cui, L.; Chan, H.K.; Zhou, Y.; Dai, J.; Lim, J.J. Exploring critical factors of green business failure based on Grey-Decision Making Trial and Evaluation Laboratory (DEMATEL). J. Bus. Res. 2019, 98, 450-461. [CrossRef]

28. Javed, S.A.; Liu, S.; Mahmoudi, A.; Nawaz, M. Patients' satisfaction and public and private sectors' health care service quality in Pakistan: Application of grey decision analysis approaches. Int. J. Health Plan. Manag. 2019, 34, 168-182. [CrossRef] [PubMed]

29. Lin, H.H. Online Group-Buying with Inventory Dependent Demand. Master's Thesis, Department of Marketing, National Chung Hsing University, Taichung, Taiwan, 2014.

30. Huang, X.R. Online Group-Buying Decision Model with Price and Inventory—Dependent Demand. Master's Thesis, Department of Marketing, National Chung Hsing University, Taichung, Taiwan, 2016.

31. Kenney, R.L. The Value of Internet Commerce to the Customer. Manag. Sci. 1999, 45, 533-542. [CrossRef] 